\title{
Revista

\section{DERECHOS TERRITORIALES Y PUEBLOS INDÍGENAS EN MÉXICO: UNA LUCHA POR LA SOBERANÍA Y LA NACIÓN}

Ramón Martínez Coria

Foro para el Desarrollo Sustentable A. C. ramarcoria@yahoo.com.mx

Jesús Armando Haro Encinas

El Colegio de Sonora aharo@colson.edu.mx

\section{RESUMEN}

El planteamiento enfoca la situación que enfrentan los pueblos indígenas de México en relación con los procesos de despojo territorial y desplazamiento forzado de poblaciones por los intereses privados, así como el impacto de estos procesos en la supervivencia de sus comunidades y la continuidad de sus patrimonios bioculturales. Buscamos hacer un recuento de los avances y limitaciones de nuestra legislación en el reconocimiento de sus derechos colectivos territoriales específicos, de acuerdo con los estándares internacionales signados por el Estado mexicano, así como su contraste con la aprobación de reformas neoliberales que atentan contra sus territorios y formas culturales, describiendo la emergencia de movimientos de lucha por la justiciabilidad de sus derechos políticos colectivos y de resistencia contra la corrupción generalizada de funcionarios y la privatización de tierras y recursos naturales.

PALABRAS CLAVE: derechos territoriales colectivos, reformas neoliberales, pueblos indígenas de México.

\section{TERRITORIAL RIGHTS AND INDIGENOUS PEOPLES IN MEXICO: A STRUGGLE FOR SOVEREIGNTY AND NATIONHOOD}

\section{ABSTRACT}

This article focuses on the situation faced by indigenous peoples in Mexico with regard to processes of territorial dispossession and forced displacement of populations in response to private interests, as well as the impact these processes have on the survival of indigenous communities and the continuity of their biocultural heritage. This article aims to report on the advances and limitations of Mexican law in recognizing specific collective territorial rights following the international standards signed by the Mexican State. These rights are also contrasted with the approved neoliberal reforms, which are an attempt against indigenous territories and cultural forms. It describes the emergence of movements that struggle for the justiciability of their collective political rights and the resistance to generalized corruption among public officials and the privatization of land and natural resources.

KEY WORDS: collective territorial rights, neoliberal reforms, indigenous peoples in Mexico. 


\title{
INTRODUCCIÓN
}

\begin{abstract}
La irrupción de la dominación del capital europeo en los países extraeuropeos, como hemos dicho, atraviesa dos etapas: primeramente la entrada del comercio y, por este medio, la incorporación de los aborígenes al intercambio de mercancías, en parte también la transformación de las formas de producción halladas en aquellos países, en producción mercantil; luego la expropiación, de un modo u otro, de la tierra de los aborígenes $y$, en consecuencia, de sus medios de producción
\end{abstract}

ROSA LUXEMBURgo, Introducción a la Economía Política, 1925

os pueblos indígenas de México enfrentan actualmente la amenaza de perder el control de sus territorios históricos a causa de la gestión indiscriminada de diversos megaproyectos de infraestructura y concesiones para la extracción masiva de recursos naturales, incluso los estratégicos para la nación, a partir de las reformas legislativas impulsadas por los últimos gobiernos. El despojo de aguas, selvas, bosques, minerales, biodiversidad y recursos energéticos conlleva el saqueo de conocimientos, acervos genéticos y técnicas que son patrimonio de sus culturas tradicionales. Significa un nuevo tipo de colonialismo interno de corte autoritario con predominio de la violación sistemática de derechos humanos, así como de la corrupción y la impunidad. Asistimos al desmantelamiento del orden constitucional basado en el derecho y el interés público como razón de Estado para ceder la soberanía al libre mercado.

El espectro de la discusión pasa por la conservación y el aprovechamiento sustentable de los recursos naturales frente al neoextractivismo. La imposición del modelo neoliberal global violenta la participación política de las comunidades y anula cualquier práctica autonómica, frente a la criminalización, cooptación e ilegalización de sus movimientos, así como la negación de sus derechos territoriales por parte del Estado. Por otro lado, el debate se extiende a la desprotección de los patrimonios bioculturales, tanto de los pueblos indígenas como de toda la nación mexicana, lo que pone en jaque rubros como el intercambio de semillas nativas, la propiedad intelectual de saberes y prácticas tradicionales y la preservación de las lenguas originarias (ONU 2013).

A pesar de los avances en el reconocimiento de los derechos humanos universales y los específicos de los pueblos indígenas en nuestro sistema constitucional, su situación social persistente a lo largo de los siglos es de pobreza extrema multidimensional, segregación en el efectivo acceso a la jurisdicción del Estado, 
desterritorialización y migración constante. Siguen enfrentando el riesgo de exterminio, reconstituyendo y resignificando sus identidades y formas de entender el mundo. Es imposible sustraer su lucha del contexto y la coyuntura nacional. En la actual crisis de ingobernabilidad sus referentes son de desigualdad, violencia y falta de seguridad jurídica.

Las reformas neoliberales fuerzan la cesión de derechos a la inversión privada sobre el control de tierras y recursos estratégicos de la nación. Los pueblos indígenas son los grupos más vulnerables al despojo y al desplazamiento forzado, a pesar de reconocerse que sus patrimonios bioculturales constituyen un reducto relevante e incluso estratégico de la soberanía nacional. Las recientes reformas a la Carta Magna y legislaciones secundarias abren paso a la intervención desmesurada y sin condicionamientos jurisdiccionales del capital y las empresas transnacionales, sin que existan apenas mecanismos efectivos que garanticen la salvaguarda de los derechos humanos.

\section{LA ENCRUCIJADA DE LOS PUEBLOS, SUS TERRITORIOS Y PATRIMONIOS BIOCULTURALES}

La importancia del territorio como condición de la identidad colectiva y sustento de los pueblos indígenas mexicanos ha sido destacada desde diferentes perspectivas coincidentes. La tierra es el elemento fundamental dentro del cual se inscribe la vida colectiva. No representa únicamente una apropiación económico-productiva o una relación utilitaria, sino una compleja construcción cosmológica y pragmática. Su territorio encarna la idea de un patrimonio colectivo, asumido en forma absoluta, exclusiva y perpetua, puesto que se transmite de generación en generación, es indivisible y no puede ser expropiado para hacerlo patrimonio inmobiliario. Es diferente de la propiedad privada, dado que no es sustituible; es una construcción simbólica consustancial a la referencia del origen y la identidad étnica, que describe una historia común ancestral arraigada a tierras y recursos colectivos. Su valor cultural difiere esencialmente del valor productivo o comercial puesto que está cargado de ese sentido único. Es ámbito de reproducción material y cultural y constituye la jurisdicción de sus prácticas autonómicas y de autogobierno (Boege 2008).

El papel de los pueblos indígenas sigue siendo la clave para la sostenibilidad en el manejo, la conservación, el aprovechamiento y la protección de los recursos naturales, los ecosistemas y los territorios comunitarios (CONABIO 2006, 
Mittermeier y Goettsch 1992). ${ }^{1}$ Numerosas investigaciones demuestran la solidez de buena parte de los conocimientos tradicionales, incluso de su superioridad en algunos ámbitos de aplicación, cuya sabiduría apenas comienza a ser apreciada como una forma de «etnociencia», por su base de observación cuidadosa y la aplicación de pruebas empíricas, la clasificación, el ensayo y el error, el diseño de hipótesis y otros procedimientos que cuestionan los juicios etnocéntricos. Como señalan Toledo y Barrera (2008), el conocimiento indígena suele especializarse en los entornos más inmediatos y es una construcción intelectual resultante de un largo proceso de acumulación de experiencias, que ha implicado que muchas personas de las comunidades probaran, desecharan o desarrollaran el uso de plantas, insectos, animales y minerales, como alimentos, medicinas, vestimenta, artículos de limpieza corporal, utensilios domésticos o materiales para la vivienda. El conocimiento etnoecológico tradicional ha sido documentado en tecnologías, saberes y experiencias en el manejo de los recursos naturales, que denotan procesos dinámicos y adaptativos a distintos ambientes o paisajes; formas de organización étnica y prácticas simbólicas únicas al interaccionar con el mundo. Hay respeto, reciprocidad, diversidad, heterogeneidad productiva, idea de armonía, animismo, trascendencia, continuidad y enfoque biocultural en el saber tradicional indígena. ${ }^{2}$

Los territorios indígenas en México han estado sujetos a distintas reconfiguraciones, desde las encomiendas y las congregaciones de pueblos, misiones y presidios en tiempos de la Colonia, hasta las reformas liberales del siglo XIX que se lograron a costa de la desprotección de las comunidades indígenas y campe-

${ }^{1}$ Los pueblos indígenas del país poseen 28 millones de hectáreas (12.4\% del territorio nacional), con $21.9 \%$ de la propiedad social del país (30000 ejidos y comunidades agrarias según Concheiro y Robles-Berlanga 2004). Las regiones indígenas son los principales asientos de la biodiversidad, como sucede en Oaxaca, Chiapas, Veracruz, Guerrero y Michoacán; 35.1\% de los bosques del país están en manos indígenas, como también más de la mitad de las selvas; las principales presas hidroeléctricas (La Angostura, Malpaso, Chicoasén, Infiernillo, Huites y Presidente Alemán) se ubican y abastecen de agua desde territorios indígenas (Boege et al. 2008, CONABIO 2006).

2 Para los pueblos indígenas la naturaleza es un ámbito sagrado y polimorfo en el que moran deidades, seres vivos y animados, con sitios especialmente numinosos que se configuran como lugares de poder, que «pueden ser entendidos como procesos simbólicos dinámicos, entretejidos con las deidades o fuerzas potentes que se manifiestan en ellos y con los rituales que allí se realizan» (Barabas 2004:114). Un correlato importante para la perspectiva biocultural es que las relaciones con la naturaleza son concebidas en un formato de reciprocidad con las entidades territoriales. La sociedad no está diferenciada de la naturaleza y ambas son imaginadas como modelo del supramundo y del inframundo; así, en el espacio celeste hay también sistema de cargos y autoridades, el mundo de abajo, de los muertos, es imaginado como el mundo terrestre. 
sinas. La reforma agraria de la revolución mexicana derivó en un reparto de las tierras indígenas en forma de ejidos, bienes comunales y pequeñas propiedades mancomunadas e individuales. Con las recientes reformas neoliberales se han sentado las bases para proceder al despojo y al desplazamiento de pueblos y comunidades, que se evidencia con la Ley de Minería de 2005, la reforma energética de 2013 y la actual propuesta de Ley de Aguas Nacionales en 2015. ${ }^{3}$ Las reformas neoliberales impiden el reconocimiento de la territorialidad indígena, puesto que permiten que las tierras en propiedad social (ejidos y comunidades) puedan convertirse en mercancías y circular libremente en el mercado, por venta, renta, asociación y otros actos mercantiles.

Se estima que existen 14.9 millones de mexicanos que se autorreconocen como indígenas (INEGI 2010). A pesar del subregistro, en las estadísticas disponibles, son ellos los que conforman los grupos de población con los peores índices de salud y acceso a servicios; la mitad de los niños no van a la escuela y los que sí van representan el mayor grado de deserción escolar, poseen dificultades de acceso a la justicia por segregación lingüística, son los que más migran en las condiciones más precarias, aunque han consolidado poderosos vínculos translocales y transnacionales que marcan las relaciones políticas y económicas con sus comunidades de origen en resistencia. Su perfil epidemiológico actual denota peores condiciones, tanto en enfermedades del rezago como emergentes (Haro y Martínez 2015).

En el entorno de una mayor presión demográfica propia de los pueblos indígenas campesinos sobre sus territorios históricos, se producen transformaciones profundas donde las generaciones de jóvenes han establecido nuevas estrategias de movilidad social y afirmación de sus identidades. La complejidad y diversidad de los escenarios en que ocurre pasa por la propagación y migración de sus comunidades lingüísticas hacia todas las ciudades del país y gran parte de Estados Unidos; la diversificación y segmentación político-religiosa y de sus sistemas normativos, la construcción de nuevas formas de organización y regu-

${ }^{3}$ En la reciente iniciativa de la nueva Ley de Aguas Nacionales (LAN), cuyo dictamen fue aprobado en comisiones y cuya votación en el pleno de la Cámara de Diputados fue aplazado hasta después de las elecciones de junio de 2015, se sientan las bases para la privatización simultánea del agua, la energía y la construcción de presas (artículos 102 y 108). Como señala Magdalena Gómez (2015), «Lo que prevalece es la apertura al capital privado mediante concesiones y contratos para la construcción, equipamiento y operación de infraestructura hidráulica. Destaca el llamado laboreo de minas, al que le serán garantizadas las aguas necesarias para sus necesidades ubicadas en el sector industrial. En contraste, al rentar sus parcelas, los comuneros y ejidatarios cederían sus derechos al agua y al pasar al dominio pleno, tendrían que solicitar una concesión». 
lación comunitaria, la creciente proporción de estudiantes indígenas en las universidades, las expresiones artísticas en plástica, música, literatura o teatro. En el contexto mexicano actual, conviene advertir que las poblaciones y comunidades indígenas ya no se circunscriben a sus territorios históricos. La mayor parte de las nuevas generaciones se ha descampesinado por urbanización y migración. Actualmente los sistemas de parentesco y redes comunitarias están multilocalizados, lo que significa la ocupación simultánea de espacios productivos y residenciales articulados, así como nuevas prácticas económicas, a veces de escala transnacional, como sucede con buena parte de la población indígena que migra al interior del país y a los Estados Unidos.

La protección, el manejo, la conservación y el control de la diversidad biocultural es asunto estratégico en México; el alto índice y la velocidad de la degradación ambiental permite vaticinar una drástica reducción de los recursos naturales en las primeras décadas del siglo XXI. ${ }^{4}$ Hay evidencias y denuncias sobre problemas socioambientales que abarcan grave contaminación de ríos, sobrexplotación de acuíferos, pérdida de biodiversidad y biomasa, avance de la desertificación, salinización de suelos, incapacidad de captación de agua pluvial y pérdida de reservas de agua fósil, deterioro o desaparición de lagunas costeras. Las nuevas legislaciones en materia ambiental y de patrimonio cultural mantienen la condición de reconocer pero no salvaguardar los derechos de los pueblos indígenas. ${ }^{5}$

${ }^{4}$ En la actualidad, $45 \%$ de los ecosistemas naturales del mundo están severamente impactados y han dejado de ser funcionales, el restante $55 \%$ sostiene los servicios ambientales para la vida del planeta y se calcula que para 2025 la cifra anterior será solo de 30\% (Ramos 2004, CENCOS 2014).

${ }^{5}$ El Convenio sobre Diversidad Biológica (CDB) de la ONU, firmado por México en 1998, señala la obligación gubernamental de integrar en su legislación nacional el respeto, la preservación de conocimiento, innovaciones, prácticas y modos de vida relevantes para la conservación y el uso sustentable de la biodiversidad. Sin embargo, los pueblos indígenas no cuentan todavía con los requisitos legales para exigir la protección de sus derechos colectivos culturales e intelectuales fuera del marco que rige el artículo 8j del CDB, diseñado para dar el control a los Estados nacionales sobre todos los conocimientos y recursos biogenéticos (Sánchez Rubio et al. 2011). El CDB es un artificio político-económico que permite transformar el patrimonio de los pueblos en bienes de capital al haber sido aprobado el Acuerdo sobre los Aspectos de los Derechos de Propiedad Intelectual Relacionados con el Comercio (APDIC), donde se establecen criterios para patentes, derechos de obtentores vegetales, secretos comerciales, derechos de autor y acuerdos de licencia de pericia, que excluyen a los pueblos indígenas, puesto que solo reconocen derechos privados y no los colectivos (Bastida et al. 2006). Las nuevas leyes tienen el objetivo de apropiarse de los recursos naturales existentes en el territorio nacional, aunque no en su forma de ecosistema, sino por medio de sus componentes químicos y biológicos. Es el caso de la Ley de Variedades Vegetales, la Ley de Bioseguridad y Organismos Genéticamente Modificados y la Ley Federal de Producción, Certificación y Comercio de Semillas. 


\section{LEGISLACIÓN, DERECHOS Y DESPOJOS TERRITORIALES}

Uno de los derechos más reclamados por pueblos y comunidades indígenas es la seguridad jurídica sobre su territorio, en términos de propiedad, manejo, conservación y aprovechamiento de sus recursos naturales. A estos se suma el derecho a la propiedad intelectual en cuanto al conocimiento tradicional en estos rubros y a la protección del patrimonio colectivo. Por ello se ha señalado que, a diferencia de otros núcleos campesinos, su territorialidad no constituye solamente una exigencia colectiva de derechos, sino que es una condición irreductible para su existencia y continuidad, un importante organizador de la vida social que permite articular la frontera entre lo individual y lo común, generalmente a través de sistemas normativos propios y concomitantes con las regulaciones estatales, como ocurre con la interpretación y aplicación de la legislación agraria y ambiental, donde la tensión con los derechos territoriales internacionalmente reconocidos está en el centro del reclamo.

Durante el siglo $\mathrm{XX}$, en el ámbito panamericano emergieron numerosos movimientos indígenas que reivindicaban autonomía y derechos al territorio. Las luchas impactaron en la opinión pública mundial y dieron origen a la discusión y la emisión de declaratorias, pronunciamientos y convenios internacionales que han puesto de relieve la obligación de los Estados de respetar la autonomía territorial. La legislación internacional suscrita por el gobierno de México contempla el derecho a las tierras y los territorios que se definen como tradicionales, así como aquellos que ocupan o utilizan de alguna manera el hábitat donde moran. Señala incluso la asignación de tierras adicionales como condición de existencia, a la vez que incluye las relaciones espirituales. Proclama el derecho de los pueblos indígenas «a participar en la utilización, administración y conservación de los recursos naturales», y «siempre que sea posible de los beneficios que reporten la explotación por parte del Estado de los recursos existentes en sus tierras», así como «recibir una indemnización equitativa por cualquier daño que puedan sufrir sus tierras como resultado de esas actividades» (OIT 1989:artículos 13-16). Reconoce la aspiración de los pueblos indígenas de asumir el control de sus propias formas de vida en condiciones políticas, económicas, sociales y culturales diferenciadas respecto de las comunidades nacionales, bajo legislación especial (CIDH 2010). No obstante las declaratorias y suscripciones signadas, México se ha distinguido por la violación generalizada de derechos humanos y está entre los 
países del continente con más denuncias por acción y omisión ante la Comisión Interamericana de Derechos Humanos (CIDH). ${ }^{6}$

La suscripción de México a convenios y tratados internacionales ha tenido gran impacto en el proceso de articulación de las movilizaciones y reivindicaciones políticas de los pueblos sobre sus derechos colectivos específicos; sin embargo, ello ocurre en un sistema jurídico que los enuncia en lo general pero escatima sistemáticamente su implantación. En el mejor de los casos, las autoridades gubernamentales solamente simulan cumplir con los derechos individuales, a pesar de los lineamientos emitidos por la Suprema Corte de Justicia de la Nación (sCJN 2013). Para la protección de intereses territoriales de los pueblos indígenas, debería ser obligatorio el proceso de consulta previa, libre e informada, antes de permitir el cambio en los usos del suelo o de hacer concesiones de obra pública y proyectos extractivos; su violación puede invalidar procesos como la presentación de un Manifiesto de Impacto Ambiental o ser causal de un amparo colectivo ante los tribunales. Lamentablemente, los procesos consultivos aún no son práctica administrativa ni de política pública en este país, no se reconoce la potestad del consultado y por lo tanto los resultados no son vinculantes para las instituciones ni para terceros, porque no se señala la obligación de respetar la decisión de los pueblos. El formato es impreciso, así como las atribuciones resultantes y las instituciones encargadas.

Es menester recordar aquí el trayecto que ha tenido la transformación constitucional y legislativa, con un paralelismo paradójico, no aleatorio sino impuesto, en cuanto a estrategia para impedir la justiciabilidad de derechos políticos y territoriales colectivos de los pueblos indígenas. El punto de referencia son las reformas federales de 1992 a los Artículos 4 y 27 constitucionales, que inscribieron en su texto por primera vez a los pueblos, a la vez que se dio lugar a la certificación de parcelas individuales, y de ese modo se vulneró la propiedad colectiva para favorecer su privatización.? Estas reformas allanaron el camino al Tratado de

${ }^{6}$ Desde 2007 la CIDH ha adoptado 39 medidas cautelares para individuos y comunidades en México. La más reciente es la MC 409/14, «Estudiantes de la Escuela Rural 'Raúl Isidro Burgos'» de Ayotzinapa, Guerrero. Por su parte, la Comisión Nacional de Derechos Humanos registró 523 agresiones a defensores de derechos humanos entre 2005 y 2011. Debido a las presiones internas y externas, la Secretaría de Gobernación creó desde 2010 el Mecanismo de Protección para Defensores de Derechos Humanos y Periodistas.

${ }^{7}$ Desde la década de 1970, las diputaciones panistas (XLII Legislatura) y posteriormente el Consejo Coordinador Agropecuario (CNA, creado en 1984) presionaron al Congreso para permitir la privatización de la propiedad social. El desprecio de los legisladores por los reclamos políticos de los pueblos indígenas se evidencia, por ejemplo, en el texto de la Ley Agraria vigente, donde se refiere 
Libre Comercio para América del Norte (TLCAN), que obligó al Estado mexicano desde su firma en 1994 a asumir cambios legislativos derivados de protocolos donde las empresas transnacionales tienen amplia participación o control en su elaboración, lo que ha derivado en el aumento de la pobreza para los pequeños productores y también el fin de la autosuficiencia alimentaria. ${ }^{8}$

A pesar de que actualmente se reconoce constitucionalmente la «composición pluricultural» de la nación mexicana, la asignatura pendiente en el sistema jurídico es el reconocimiento pleno de los pueblos indígenas como sujetos colectivos de derecho público, en cumplimiento con los convenios internacionales, así como de los Acuerdos de San Andrés firmados por el Ejecutivo federal con el Ejército Zapatista de Liberación Nacional (EZLN) en 1996. La contrarreforma de 2001 al Artículo 2 constitucional solamente los reconoció como sujetos de interés público pero no su personalidad jurídica, ni sus derechos territoriales, ni su representación política como pueblos y comunidades indígenas, los redujo a usuarios de programas de gobierno. El reconocimiento de sus derechos lingüísticos en 2003 no permite un ejercicio cabal en vista de la ambigüedad con que define la titularidad de estos derechos (López 2009).

Además de la negativa a reconocer el derecho de los pueblos indígenas a sus territorios y los recursos naturales en ellos existentes, el Estado mexicano ha instrumentado una serie de procedimientos o rutas para permitir que se despoje a los pueblos de sus tierras e impedirles el acceso a recursos estratégicos. A pesar de que contradicen modificaciones constitucionales efectuadas, los dispositivos legales para el despojo tienden a consolidarse con la reciente ronda de reformas impulsadas por el régimen neopriísta, como la controvertida reforma energéti-

las tierras y territorios indígenas como «hábitat», una categoría no jurídica. Las reformas agrarias no solo dieron por terminado el reparto sino que otorgaron a las asambleas ejidales la facultad de delimitar y decidir el destino de las tierras, mientras que el Programa de Certificación de Derechos Ejidales y Titulación de Solares Urbanos (PROCEDE) se implantó desde 1994 para permitir la certificación individual de parcelas y su posterior venta, con lo que se desprotegió la posesión colectiva de los núcleos agrarios y la transmisión de sus tierras como patrimonio familiar y comunitario. Se transformaron las instituciones del otrora llamado «sector agrario», para extinguir la Secretaría de la Reforma Agraria (SRA) y incorporar a la Procuraduría Agraria (PA) y al Registro Agrario Nacional (RAN) en la nueva Secretaría de Desarrollo Agrario, Territorial y Urbano (SEDATU).

${ }^{8}$ En realidad, las reformas neoliberales comenzaron con la apertura comercial del GATT en 1982. Numerosas investigaciones han demostrado el impacto negativo que ha tenido el Tratado de Libre Comercio de América del Norte como las reformas agrarias comentadas, en comunidades rurales de pequeña escala, con graves consecuencias negativas para la alimentación, las condiciones de salud y calidad de vida de los pueblos indígenas (Chacón, Durand y Fernández 1995, Cornelius y Myhre 1998, De Grammont y Tejera 1996). 


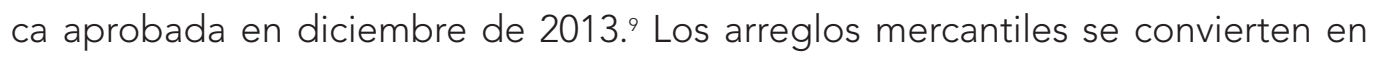
nuevas rutas jurídicas para el despojo, como sucede con el arrendamiento de la propiedad social, que ahora recibe el eufemismo de «contrato de asociación o aprovechamiento» y «ocupación temporal».

Las formas de despojo territorial actuales incluyen la compra-venta de tierras y la traslación de dominio, así como contratos de usufructo, formas que no requieren intervención estatal porque son actos entre particulares. Pese a los avances en la parcelización agraria, como señala Robles Berlanga (2012), según datos recientes apenas se había vendido $2.9 \%$ de los 105 millones de hectáreas que pertenecen a ejidos y comunidades. Cerca de $70 \%$ de los núcleos agrarios que decidieron ingresar en el Programa de Certificación de Derechos Ejidales lo hicieron para definir la perimetral y no parcelaron, mantuvieron sus tierras de uso común y decidieron mantener la propiedad colectiva. ${ }^{10}$

El Estado interviene de otras maneras que suelen ser unilaterales, como la expropiación, la concesión para la extracción de los recursos naturales y la imposición de modalidades legales. ${ }^{11}$ La expropiación alude a la facultad vertical estatal de privar a los propietarios, privados o sociales, del uso, goce, disfrute y disposición de sus bienes «por causa de utilidad pública». Ha sido el mecanismo más socorrido para llevar a cabo grandes obras públicas en territorios indígenas que luego se entregan a los particulares para su usufructo, como ha sido el caso de presas hidroeléctricas, carreteras y otros proyectos. ${ }^{12}$ Una concesión refiere a

${ }^{9}$ La Ley de Aguas Nacionales, la Ley General de Equilibrio Ecológico y Protección al Ambiente, la Ley de Desarrollo Forestal Sustentable, la Ley Minera y la Ley General de Asentamientos Humanos, tienen incidencia en las tierras y los recursos naturales, como también las leyes del Servicio Público de Energía Eléctrica, de Energía Geotérmica, Hacendaria, de Inversión Extranjera, de Amparo, de Expropiación, de Bienes Nacionales, Laboral, de Órganos Reguladores en Materia Energética, de Asociaciones Público y Privadas; así como de la nueva Agencia Nacional de Seguridad Industrial y de Protección al Medio Ambiente, que junto con otras reformas, como la de Educación y la de Telecomunicaciones, han sido presentadas y aprobadas sin la participación de los pueblos indígenas y sin la ciudadanía.

${ }^{10}$ Según datos del Registro Agrario Nacional (RAN), hasta el año 2000 se inscribieron 35803 actos de enajenación de tierras, mientras para 2008 la cifra había aumentado a 62055, un incremento de 73.3 por ciento.

${ }^{11}$ El interés privado se hace pasar por interés público gracias a la manera en que es definido este último en el artículo 27 reformado y sus leyes reglamentarias. El «interés público» se esgrime como argumento para el despojo de los pueblos en varias de las leyes secundarias, incluyendo mineras y energéticas.

${ }^{12}$ Así ha sucedido, por citar algunos ejemplos, con las presas hidroeléctricas de Miguel Alemán y Cerro de Oro, en Oaxaca (Bartolomé y Barabas 1990), Luis Donaldo Colosio, en Sinaloa; la Angostura y Chicoasén, en Chiapas; la del Caracol, en Guerrero y la 02 en el estado de Hidalgo. Estas obras 
un acto mediante el cual la administración pública otorga a particulares permisos para explotar un bien que es propiedad del Estado (Nava y Quiroz 2007:687).

Aunque no existen datos precisos, se estima que entre una tercera y una cuarta parte del territorio nacional ha sido concesionado a las mineras. ${ }^{13}$ Actualmente se encuentran numerosos proyectos en etapa de explotación y prospección en regiones indígenas de Sonora, Chihuahua, Durango, Puebla, Guerrero, Jalisco, Nayarit y Chiapas (CGM 2007, Del Val 2014, Becerril 2014). Según Sariego (2010), en las sierras Madre Occidental y Madre Oriental se está configurando una tercera frontera minera, ubicada en lugares recónditos de las cadenas montañosas, generalmente controlados por los cárteles del narcotráfico u otras expresiones del crimen organizado. ${ }^{14}$

Otra forma de despojo territorial es la imposición de modalidades legales, que se traducen en limitaciones o transformaciones del derecho de propiedad. Existen leyes para reglamentar la explotación de las tierras, aguas, minas, vida silvestre, recursos forestales, flora y fauna, sanidad animal y sanidad vegetal, lo cual incluye nuevas leyes sobre variedades vegetales y organismos genéticamente

desplazaron a miles de personas, en su mayoría indígenas, y provocaron un deterioro ambiental del que nadie se hizo responsable. Otros megaproyectos incluyen al Plan Puebla-Panamá (PPP), el Eje Transísimico con el «Programa Integral de Desarrollo Económico para el istmo de Tehuantepec (Oaxaca-Veracruz)» y el tren transpeninsular en Yucatán (Robinson 2012), recientemente cancelado.

${ }^{13}$ Las concesiones benefician principalmente a empresas canadienses, así como inglesas, estadounidenses, australianas, chinas, indias, japonesas y mexicanas. Aunque la reciente reforma a la Ley Minera aumentó la contribución fiscal a 7\%, el régimen de excepción en el que operan las compañías provoca que se lleven prácticamente gratis la mayor parte de sus ganancias. La minería produce $64 \%$ de los contaminantes tóxicos a escala nacional, seguida por centrales eléctricas y maquila de equipo electrónico. Incluye principalmente plomo, ácido sulfhídrico, cadmio, cromo, níquel y cianuro, según el Registro de Emisiones y Transferencia de Contaminantes (RETC) de 2005 (Navarro 2014).

${ }^{14}$ Los territorios indígenas más golpeados en términos de la extensión de las concesiones son los rarámuris, binnizá (principalmente de los valles centrales de Oaxaca), cha'cña (chatinos), ñuu sabih (mixtecos), nayerii (coras) y odami (tepehuanes). Juntos suman más de un millón de hectáreas en donde los indígenas pierden el control sobre sus territorios y representan la mitad de todas las concesiones en territorios indígenas. Algunas concesiones abarcan casi la totalidad de los terrenos de los pueblos con demografías pequeñas, como ko'lew (kiliwas), oob (pimas), mahkurawe (guarijíos de Sonora), kikapoos, espei (cucapá) y nahuas de Michoacán (Boege 2013). Según Jaime Martínez Veloz (Becerril 2014), Comisionado para el Diálogo con los Pueblos Indígenas había, hasta 2014, 857 proyectos de explotación y extracción distribuidos en 16 estados del noroeste: Sonora (206), Chihuahua (120), Durango (97), Sinaloa (85) y Zacatecas (66). El artículo 6 de la ley minera impuesta por el Banco Mundial y por los presidentes Salinas, Fox y Calderón, señala que la explotación del subsuelo es de «interés público prioritario», y que este interés predomina sobre otros intereses públicos y privados no mineros (López Bárcenas y Eslava 2013). 
modificados. Aunque hablan de protección y promoción de derechos territoriales y patrimoniales, en realidad están diseñadas para desregular la protección anterior como patrimonio de la nación y así facilitar su apropiación privada. De hecho, en México ya se usan esas tensiones de sentido en la trama legal para impedir que pueblos indígenas y campesinos puedan ejercer plenamente sus derechos colectivos. ${ }^{15}$

La lógica del mercado esconde la explotación impuesta, el despojo violento, la represión con la fuerza pública, el desplazamiento forzado, la discriminación sistémica y el desprecio de los gobernantes. La revolución tecnológica e informática trajo consigo la posibilidad de la simultaneidad y la omnipresencia del capital, fundamentalmente de su sector más emblemático: el capital financiero. Su dinámica determina ahora las relaciones internacionales y las internas de los cada vez más débiles Estados nacionales. Los arreglos mercantiles se convierten en nuevas rutas jurídicas para el despojo de territorios indígenas, como pasa con el arrendamiento de la propiedad social, que puede efectuarse con particulares o con el Estado, tanto de manera total respecto de tierras colectivas, o por parcelas, directamente con ejidatarios o comuneros, para todo tipo de empresas. ${ }^{16}$

${ }^{15}$ Es cierto que el artículo 27 y la Ley Agraria establecen disposiciones de protección especial y acceso preferencial a los recursos naturales para los indígenas, pero no existen mecanismos claros de protección, solo señalamientos indefinidos sin soporte legal ni reglamentos secundarios. El caso del pueblo espéi es emblemático, al impedírseles pescar debido a que su lugar ancestral quedó incluido en la zona núcleo de la Reserva de la Biosfera Alto Golfo de California y Delta del Río Colorado. Otros casos responden a un despojo productivo, como el que afecta a los ti'pai (kumiai), asentados en el Valle de Guadalupe, B.C., donde las comunidades San Antonio Necua y San José de la Zorra mantienen demandas penales por despojo de tierras y agua, debido a permisos otorgados por la Comisión Nacional del Agua (CONAGUA) a viticultores particulares (Lamas y Martínez 2013).

${ }^{16}$ Los cambios a los artículos 27 y 28 constitucionales eliminan la prohibición para ofrecer contratos de explotación, producción y manejo de hidrocarburos y generación de electricidad a empresas privadas, nacionales o transnacionales. Su carácter estratégico hace que estas actividades se declaren de interés social y orden público y tengan prioridad y preferencia sobre cualquiera que se realice en el suelo y subsuelo del territorio nacional. Se eliminan las restricciones para el capital privado con la incorporación de la figura de empresas productivas del Estado, en cuyos consejos de administración no tienen cabida los sindicatos. Se facilitan condiciones para la extracción de gas y minerales del subsuelo, incluyendo el fracking, una tecnología de explotación no convencional que fractura el suelo que para extraer gas lutita requiere grandes volúmenes de agua en un procedimiento altamente contaminante. Se han concesionado casi 5 millones de hectáreas en el actual gobierno (2012-2018) para la explotación petrolera, con las Rondas Cero y Uno, con grave afectación de territorios indígenas slijuala sihanuk (chontales), tachihuiin (totonacos), núntahá (popolucas), téenek (huastecos) y nahuas (Ánimas 2014). 


\section{CONFLICTOS SOCIOAMBIENTALES Y ESTRATEGIAS DE DEFENSA TERRITORIAL}

Es importante considerar la variedad de formas de expresión que asumen las luchas de los pueblos indígenas y campesinos, como las de defensa y resistencia a las amenazas que enfrentan sus territorios y estilos de vida. Reconocer que han emergido numerosas estrategias de respuesta creativas y adaptativas por parte de las comunidades, desde aquellas de carácter defensivo para evitar la implantación de proyectos destructivos o mitigar sus impactos, hasta las que impulsan proyectos alternativos al modelo dominante, lo cual abarca prácticas productivas sustentables, uso y rescate del conocimiento tradicional, así como protección de los patrimonios bioculturales en su diversidad. Sobresale la defensa de la integridad comunitaria, así como procesos para reconfigurar el ejercicio del poder interno. Otras batallas incluyen su derecho a ser reconocidos como pueblos étnicamente diferenciados, tener sus propias formas de autogobierno y participar en la vida nacional de manera distinta al resto de la población.

Los conflictos por territorios y recursos naturales que actualmente hay en México pueden visualizarse según el tipo de actividad e impacto ecológico asociado. Siguiendo a Toledo et al. (2014), se identifican graves deterioros agro-ecológicos debidos a contaminación, sobrexplotación de mantos acuíferos, desvío de aguas a ciudades e industrias, introducción de transgénicos y erosión de suelos. ${ }^{17}$ Las luchas generadas por el control de los recursos energéticos constituyen otro tipo de problemas, como los asociados a proyectos termoeléctricos, presas, hidroeléctricas, parques eólicos y plantas de energía nuclear, que son de gran impacto, al igual que los desarrollos turísticos y otros grandes proyectos. Todos estos modos de intervención afectan la biodiversidad y los ecosistemas, y en otro sentido ponen en riesgo el acceso de los pueblos a sus manantiales, panteones y lugares sagrados.

Hay otro tipo de conflictos territoriales y socioambientales que involucran a los pueblos indígenas, como los que corresponden a las enormes obras de infraestructura pública y privada o a la extracción masiva de recursos naturales. Disputas, amenazas y riesgos que surgen por la construcción de carreteras, gasoductos, acueductos, presas, megaproyectos inmobiliarios, complejos comer-

${ }^{17}$ Las corporaciones Monsanto, Dupont y Pioneer «han logrado la siembra de campos experimentales de maíz genéticamente modificado en México, que es el área de origen de este cereal. Esto representa un alto riesgo, pues se ponen en peligro a numerosas variedades nativas, que son la base de la alimentación de los mexicanos. A la fecha se han realizado 195 experimentos con MT en los estados de Sonora, Sinaloa, Chihuahua y Tamaulipas» (Toledo et al. 2013:118). 
ciales y turísticos, así como la apertura de nuevas áreas para agrocultivos y prospección de aprovechamientos, incluso en áreas naturales protegidas (Salas et al. 2011). Algunos ejemplos emblemáticos son la carretera Tuxtepec-Huatulco y el corredor turístico Chinanteco, en Oaxaca; la autopista San Cristóbal-Palenque y la Reserva de Montes Azules en Chiapas, la ampliación de la autopista La PeraCuautla en Morelos y Naucalpan-Toluca en el Estado de México. Las obras generan fuerte oposición, como la lucha de San Salvador Atenco contra el proyecto de aeropuerto para la Ciudad de México. Igualmente relevantes son el gasoducto El Encino-Topolobampo de Sinaloa a Chihuahua, recientemente parado por los rarámuris, y el gasoducto Morelos, que pretende atravesar Puebla, Tlaxcala y Morelos. Destaca la lucha de los pueblos ikoot (huave) y binnizá (zapoteco) frente a la pretensión del gobierno del estado de Oaxaca y la empresa Mareña Renovable de construir el Corredor Eólico del Istmo. En cuanto a los conflictos turísticos, algunos son el de Tatei Haramara, zona sagrada de los wixárika en Nayarit, los complejos turísticos en las cascadas de Agua Azul, en Bachajón, Chiapas y Barranca del Cobre en la sierra Tarahumara de Chihuahua, donde la comunidad de Mogotavo enfrenta un litigio contra empresarios que también son políticos. Hay conflictos mineros relevantes que sostienen actualmente pueblos indígenas como los comca'ac (seris) y tohono otham (pápagos) en Sonora; los odami y rarámuris de Chihuahua, y Durango, así como en otras regiones de todo el país.

Entre las estrategias defensivas se encuentra la organización colectiva que se genera a partir de diversos aprendizajes comunitarios, que incluyen diligencias administrativas, judiciales, milicianas y de diálogo político. Tanto el posible desplazamiento como la afectación al territorio, son riesgos verificables, susceptibles de ser desactivados por la vía de la gestión política y jurídica. En este sentido es relevante recurrir al derecho internacional humanitario (DIH) y los derechos humanos universales (DHU) como medidas no solamente preventivas sino como elementos pertinentes en la negociación de alternativas y soluciones duraderas. El Alto Comisionado de las Naciones Unidas para los Derechos Humanos (ACNUDH) ha interpelado al gobierno mexicano en demanda de garantías para generar espacios de diálogo político con las comunidades y organizaciones indígenas, derivar acuerdos concretos, viables, verificables y efectivos para la resolución de conflictos y protección de sus derechos humanos. Ha demandado que se ponga límite a megaproyectos y concesiones que implican la extracción masiva de recursos naturales o bien, la afectación y ocupación de tierras de vocación pro- 
ductiva que atenten contra la integridad de los patrimonios territoriales y bioculturales de los pueblos originarios.

En el entorno de estas convenciones hay otros instrumentos a partir de los cuales los pueblos indígenas han peleado sus derechos territoriales más allá de la jurisdicción de los Estados nacionales, específicamente ante el fuero del Sistema Interamericano de Derechos Humanos, donde la Corte Interamericana ha generado jurisprudencia y resoluciones vinculantes para la protección jurídica de los territorios de los pueblos indígenas. A finales de 1996 la CIDH tomó nota de la primera audiencia temática en materia agraria contra el Estado mexicano por parte del Panel de Inspección del Banco Mundial, interpuesta por organizaciones de la sociedad civil y ejidos yoremes (mayos) respecto de la presa Huites / Luis Donaldo Colosio, en Choix, Sinaloa (López et al. 1996, Martínez 1999). La Comisión conoció el reclamo por violación de derechos como efecto de la reforma constitucional al Artículo 27 y la legislación agraria de 1992. Desde entonces se documentan cientos de casos en litigio en los tribunales agrarios mexicanos, así como litigios estratégicos ante la jurisdicción de la Organización de Estados Americanos.

Hay otros elementos jurídicos utilizados, como los Principios Rectores para Desplazamientos Internos y los Principios Pinheiro para Soluciones Duraderas a Desplazados, así como la Convención Internacional sobre la Eliminación de todas las Formas de Discriminación Racial o las Directrices Operacionales del Banco Mundial sobre Poblaciones Indígenas, para reparaciones de daños y compensaciones por efectos de expropiaciones y desplazamientos por grandes obras de infraestructura. Como puede apreciarse en el cuadro 1, las formas de defensa ensayadas por los pueblos en México abarcan un amplio abanico de estrategias.

Cuadro 1. Estrategias de defensa de territorios indígenas en México.

\begin{tabular}{|c|c|c|c|c|}
\hline Estrategias & Objetivo & Nivel & Ámbito de acción & Notas \\
\hline $\begin{array}{l}\text { Organización } \\
\text { comunitaria }\end{array}$ & $\begin{array}{l}\text { Que los pueblos se } \\
\text { encuentren organiza- } \\
\text { dos, con sus autorida- } \\
\text { des establecidas }\end{array}$ & Local & $\begin{array}{l}\text { Asambleas, reunio- } \\
\text { nes para concientizar }\end{array}$ & $\begin{array}{l}\text { Gestionar reglamentos } \\
\text { internos en ejidos y co- } \\
\text { munidades }\end{array}$ \\
\hline $\begin{array}{l}\text { Capacitación } \\
\text { en derechos }\end{array}$ & $\begin{array}{l}\text { Que los sujetos de } \\
\text { derecho tengan co- } \\
\text { nocimiento de sus } \\
\text { derechos }\end{array}$ & Local & $\begin{array}{l}\text { Asambleas, talleres, } \\
\text { cursos }\end{array}$ & $\begin{array}{l}\text { «Educación descoloni- } \\
\text { zadora», Socializar he- } \\
\text { rramientas: Convenio } \\
\text { 169, Derechos huma- } \\
\text { nos, constitución, etc. }\end{array}$ \\
\hline
\end{tabular}




\begin{tabular}{|c|c|c|c|c|}
\hline Estrategias & Objetivo & Nivel & Ámbito de acción & Notas \\
\hline $\begin{array}{l}\text { Capacitación } \\
\text { en su territorio }\end{array}$ & $\begin{array}{l}\text { Que los «afectables» } \\
\text { conozcan los recursos } \\
\text { propios }\end{array}$ & Local & $\begin{array}{l}\text { Asambleas, talleres, } \\
\text { cursos, inventarios, } \\
\text { mapas }\end{array}$ & $\begin{array}{l}\text { Elaborar conjuntamen- } \\
\text { te una descripción del } \\
\text { territorio indígena y sus } \\
\text { recursos }\end{array}$ \\
\hline $\begin{array}{l}\text { Capacitación } \\
\text { en el proyecto } \\
\text { de «desarrollo» }\end{array}$ & $\begin{array}{l}\text { Que conozcan los } \\
\text { impactos potenciales } \\
\text { del proyecto }\end{array}$ & Local & $\begin{array}{l}\text { Reuniones informa- } \\
\text { tivas, exigir proyecto } \\
\text { y resumen en lengua } \\
\text { indígena }\end{array}$ & $\begin{array}{l}\text { Realizar foros de aná- } \\
\text { lisis, solicitar peritajes. } \\
\text { Exigir proyecto deta- } \\
\text { Ilado, licitación, planes } \\
\text { de manejo, etc. } \\
\text { (promotores, IFAI) }\end{array}$ \\
\hline $\begin{array}{l}\text { Defensa del } \\
\text { territorio }\end{array}$ & $\begin{array}{l}\text { Crear grupos organi- } \\
\text { zados que resistan ac- } \\
\text { tivamente la invasión }\end{array}$ & Local & $\begin{array}{l}\text { Policías comunitarias, } \\
\text { acciones concerta- } \\
\text { das, etc. }\end{array}$ & $\begin{array}{l}\text { «Defensas comunita- } \\
\text { rias» para vigilancia, } \\
\text { registro de visitas, boi- } \\
\text { cot a empresas }\end{array}$ \\
\hline $\begin{array}{l}\text { Mediación de } \\
\text { conflictos intra- } \\
\text { comunitarios }\end{array}$ & $\begin{array}{l}\text { Solucionar conflictos } \\
\text { internos de interés }\end{array}$ & Local & $\begin{array}{l}\text { Talleres, visitas, } \\
\text { asambleas, otras } \\
\text { estrategias de me- } \\
\text { diación. }\end{array}$ & $\begin{array}{l}\text { Requiere expertos en } \\
\text { mediación. }\end{array}$ \\
\hline $\begin{array}{l}\text { Movilización } \\
\text { comunitaria }\end{array}$ & $\begin{array}{l}\text { Acciones de visibiliza- } \\
\text { ción y protesta }\end{array}$ & $\begin{array}{l}\text { Local- } \\
\text { regional }\end{array}$ & $\begin{array}{l}\text { Tomas de instalacio- } \\
\text { nes, bloqueos, mani- } \\
\text { festaciones, marchas, } \\
\text { etcétera. }\end{array}$ & $\begin{array}{l}\text { Expulsar a promotores } \\
\text { de comunidad, parar } \\
\text { las obras }\end{array}$ \\
\hline $\begin{array}{l}\text { Difusión me- } \\
\text { diática }\end{array}$ & $\begin{array}{l}\text { Impactar en la opi- } \\
\text { nión pública }\end{array}$ & Regional & $\begin{array}{l}\text { Medios, especial- } \\
\text { mente alternativos } \\
\text { (radios comunitarias) }\end{array}$ & $\begin{array}{l}\text { Denuncias públicas. } \\
\text { Producción de materia- } \\
\text { les propios }\end{array}$ \\
\hline $\begin{array}{l}\text { Alianzas estra- } \\
\text { tégicas }\end{array}$ & Establecer aliados & Regional & $\begin{array}{l}\text { Encuentros, comu- } \\
\text { nicación, acciones } \\
\text { conjuntas }\end{array}$ & $\begin{array}{l}\text { Resistencias similares, } \\
\text { organismos civiles, } \\
\text { académicos, persona- } \\
\text { lidades }\end{array}$ \\
\hline $\begin{array}{l}\text { Movilización } \\
\text { redes sociales }\end{array}$ & $\begin{array}{l}\text { Impactar en la opi- } \\
\text { nión pública }\end{array}$ & Múltiple & Internet & $\begin{array}{l}\text { Facebook, Twitter, } \\
\text { Whatsapp, blogs, } \\
\text { Youtube, etcetera. }\end{array}$ \\
\hline $\begin{array}{l}\text { «Diálogo polí- } \\
\text { tico» }\end{array}$ & $\begin{array}{l}\text { Negociaciones entre } \\
\text { comunidad y promo- } \\
\text { tores de obras }\end{array}$ & $\begin{array}{l}\text { Local- } \\
\text { regional }\end{array}$ & $\begin{array}{l}\text { Reuniones, acuerdos, } \\
\text { incorporación de ob- } \\
\text { servadores }\end{array}$ & $\begin{array}{l}\text { Implica asesoría técni- } \\
\text { ca y legal a las comuni- } \\
\text { dades. }\end{array}$ \\
\hline $\begin{array}{l}\text { Acompaña- } \\
\text { miento organi- } \\
\text { zaciones civiles, } \\
\text { sindicales, } \\
\text { campesinas, } \\
\text { académicas, } \\
\text { internacionales, } \\
\text { etcétera. }\end{array}$ & $\begin{array}{l}\text { Obtener observación } \\
\text { de instancias relevan- } \\
\text { tes }\end{array}$ & Múltiple & $\begin{array}{l}\text { Encuentros, comu- } \\
\text { nicación, acciones } \\
\text { conjuntas }\end{array}$ & $\begin{array}{l}\text { Pretende obtener ase- } \\
\text { soría y acompañamien- } \\
\text { to experto }\end{array}$ \\
\hline
\end{tabular}




\begin{tabular}{|c|c|c|c|c|}
\hline Estrategias & Objetivo & Nivel & Ámbito de acción & Notas \\
\hline $\begin{array}{l}\text { Acciones jurí- } \\
\text { dico-adminis- } \\
\text { trativas ante el } \\
\text { Estado }\end{array}$ & $\begin{array}{l}\text { Exigir derechos, de- } \\
\text { nunciar situaciones }\end{array}$ & & $\begin{array}{l}\text { Gestiones adminis- } \\
\text { trativas: oficios de } \\
\text { inconformidad, au- } \\
\text { diencias, visitas de } \\
\text { campo, etc. }\end{array}$ & $\begin{array}{l}\text { Derecho de petición } \\
\text { P.I.; exigir consulta }\end{array}$ \\
\hline $\begin{array}{l}\text { Consulta pre- } \\
\text { via, libre e in- } \\
\text { formada }\end{array}$ & $\begin{array}{l}\text { Obtener elementos } \\
\text { de defensa posterior }\end{array}$ & Local & $\begin{array}{l}\text { Organización propia, } \\
\text { reglamento inclusivo }\end{array}$ & $\begin{array}{l}\text { Establecer sujetos con } \\
\text { interés legítimo, pla- } \\
\text { zos, formatos }\end{array}$ \\
\hline \multicolumn{5}{|l|}{$\begin{array}{l}\text { Recursos pro- } \\
\text { cesales }\end{array}$} \\
\hline Amparo & Detener obras & & & \\
\hline Juicios agrarios & $\begin{array}{l}\text { Emplazar a juicio y } \\
\text { solicitar solución de } \\
\text { irregularidades e in- } \\
\text { justicias. }\end{array}$ & $\begin{array}{l}\text { Federal / es- } \\
\text { tatal }\end{array}$ & $\begin{array}{l}\text { Tribunal Agrario, Pro- } \\
\text { curaduría agraria }\end{array}$ & $\begin{array}{l}\text { Aplica en ejidos, co- } \\
\text { munidades y otras } \\
\text { sociedades colectivas } \\
\text { territoriales }\end{array}$ \\
\hline $\begin{array}{l}\text { Cuestionar el } \\
\text { M.I.A. }\end{array}$ & $\begin{array}{l}\text { Solicitar consulta a } \\
\text { SEMARNAT, reuniones } \\
\text { publicas }\end{array}$ & Federal & $\begin{array}{l}\text { SEMARNAT, } \\
\text { PROFEPA }\end{array}$ & \\
\hline $\begin{array}{l}\text { Cuestionar el } \\
\text { cambio de uso } \\
\text { de suelo }\end{array}$ & & Federal & $\begin{array}{l}\text { SEMARNAT, } \\
\text { PROFEPA, CONABIO }\end{array}$ & \\
\hline $\begin{array}{l}\text { Cuestionar pla- } \\
\text { nes de manejo } \\
\text { ambiental }\end{array}$ & $\begin{array}{l}\text { Revisar los condicio- } \\
\text { nantes del resolutivo } \\
\text { MIA }\end{array}$ & Federal & $\begin{array}{l}\text { SEMARNAT, } \\
\text { PROFEPA, CONABIO }\end{array}$ & \\
\hline $\begin{array}{l}\text { Solicitar medi- } \\
\text { das cautelares }\end{array}$ & $\begin{array}{l}\text { Pedir protección in- } \\
\text { ternacional vinculante }\end{array}$ & Internacional & $\mathrm{CIDH}, \mathrm{ONU}$ & \\
\hline
\end{tabular}

Fuente: Elaboración propia.

El caso de resistencia de la tribu yoeme (yaqui) frente al despojo de agua para el Acueducto Independencia por parte del gobierno de Sonora es un ejemplo de combinación de estrategias de defensa que incluyen juicios de amparo, impugnación del Manifiesto de Impacto Ambiental y bloqueo de la carretera internacional, además de difusión y apoyo nacional e internacional (Moreno 2014).18 Por otro lado, las comunidades wixárika de la Sierra Madre de Jalisco lograron por

${ }_{18}$ Otros conflictos por proyectos de transferencia de aguas entre cuencas son Monterrey $\mathrm{VI}$ (Nuevo León), El Zapotillo (Jalisco-Guanajuato), Costa de Oro (Nayarit-Sinaloa), Bandera Blanca (Veracruz), Huexca (Morelos), el acueducto Presa Lázaro Cárdenas-La Laguna, en Durango y la etapa IV del Sistema Lerma-Cutzamala. 
vía judicial la suspensión de las obras de extracción de mineral concedidas por el gobierno federal a una compañía canadiense en territorios ejidales mestizos del desierto de Matehuala en San Luis Potosí, donde se ubican sus lugares sagrados. ${ }^{19}$ En nuestra experiencia con el pueblo guarijío de Sonora y su lucha contra el proyecto de presa Los Pilares, iniciada en 2014, hemos implementado también una combinación de estrategias que siguen en pie (Haro 2013).

Son emblemáticos los casos de resistencia a la construcción de varias presas, como Paso de la Reina en Oaxaca y La Parota en Guerrero, donde los esfuerzos movilizados no se han circunscrito a la población indígena sino que se han extendido a toda la región, como en El Zapotillo en Jalisco (Espinoza 2012), Las Cruces en Nayarit (Castillo 2013), El Picacho en Sinaloa y otras más (Nahmad 2001); en algunos de estos proyectos, como en La Yesca y El Cajón en Nayarit, así como El Zapotillo, se encuentran procesos judiciales por violación al derecho de consulta previa, libre e informada de las comunidades afectadas. También es relevante mencionar la defensa de los bosques de la comunidad purépecha de Cherán, Michoacán, puesto que el Tribunal Electoral Federal (TRIFE) reconoció los derechos político-electorales de un conjunto de ciudadanos por su diferencia étnica, para llevar a cabo el proceso electoral de acuerdo con sus prácticas culturales (Campanur 2014).

Los movimientos de resistencia son tan numerosos como los propios megaproyectos. Algunos de ellos están organizados en redes más amplias, que en conjunto agrupan casi 300 organizaciones regionales, como la Asamblea Nacional de Afectados Ambientales (ANNA), el Tribunal Permanente de los Pueblos en México, la Red Mexicana de Afectados por la Minería (REMA), el Movimiento Mexicano de Afectados por las Presas y en Defensa de los Ríos (MAPDER), la Red Sin Maíz No Hay País, la Alianza Mexicana por la Autodeterminación de los Pueblos, la Asamblea de los Pueblos Indígenas del Istmo de Tehuantepec en Defensa de la Tierra y el Territorio, la Unión de Pueblos de Morelos, Puebla y Tlaxcala, la Unión de Comunidades Indígenas de la Zona Norte del Istmo, entre otras. Desde finales de la década de 1980 han aparecido movimientos con enfoque autonómiCo, como el Frente Independiente de Pueblos Indios (FIPI), el Frente Nacional de Pueblos Indígenas (PRENAPI), el Congreso Nacional Indígena (CNI) y la Asamblea Nacional Plural por la Autonomía (ANIPA), organismos que no han logrado integrar

${ }^{19}$ En este territorio se ubica Wirikuta, conjunto de lugares sagrados para los pueblos serranos. El Tribunal aceptó un recurso de amparo agrario que por primera vez protegió el principio de territorio simbólico como patrimonio cultural de un pueblo indígena que no se asienta residencialmente en esas tierras, sino que configura su territorio de cacería ritual y una de las orillas del Mundo. 
una línea conjunta de acción y que, en cierta medida, han sido cooptados o reprimidos por el régimen político, aunque permanecen en la búsqueda de construir un movimiento nacional de base indígena para la defensa de los Acuerdos de San Andrés sobre derechos y cultura indígenas y los resolutivos de los foros indígenas derivados (López s.f.). ${ }^{20}$

Articuladas a la defensa de sus derechos territoriales, las estrategias de autogestión y construcción de autonomías pasan por nuevos paradigmas frente a la crisis del concepto de desarrollo y la constatación del fracaso en la lucha contra la pobreza y la inequidad generada por los gobiernos nacionales. Han emergido expresiones propias de los pueblos indígenas para caracterizar sus expectativas de transformación, como el concepto winik atel (tseltal) de lekil kuxlejal (buen vivir), que promulga una relación armónica entre la gente y la Madre Tierra, el mixteco nava ku ka'anu +n ñuú ñuúsavi o el andino sumak kawsay (buena vida) incluido en las constituciones de Ecuador (2008) y Bolivia (2009). Para algunos autores, estos conceptos constituyen «la única alternativa al discurso neoliberal del desarrollo y el crecimiento económico» (Dávalos 2008), sin dejar de advertir que siendo alternativos pueden representar «solo formas de resistencia más que propuestas de emancipación» (López 2013).

Las resistencias y estrategias de defensa territorial de los pueblos indígenas del país han avanzado significativamente en tiempos recientes con formas novedosas y creativas que tienden a enlazarse. En algunas regiones se han adoptado acciones no convencionales encaminadas a la búsqueda del bienestar y la calidad de vida desde las propias comunidades, en ámbitos tan heterogéneos como producción, consumo, comercialización, construcción de viviendas, salud, manejo de riesgos socioambientales, rescate de saberes tradicionales, alimentación, nutrición y gastronomía, control de plagas, etc. Suelen funcionar con criterios de economía social y en ámbitos no dominados por el mercado global. Se basan en

20 Desde la década de los setenta el Estado mexicano ha impulsado la coordinación de la representación indígena, inicialmente con la creación, en 1973, del Movimiento Nacional Indígena (MNI), con participación mayoritaria de profesores bilingües, y desde 1975, el Consejo Nacional de Pueblos Indígenas (CNPI), integrado por los Consejos Supremos que se crearon de manera corporativa por todo el país. Fue en la década de los ochenta cuando comenzaron a formarse organizaciones —en su mayoría regionales - que levantaron demandas fuera de los cauces institucionales (López Bárcenas s.f.). Así, se conformaron varias organizaciones autogestivas, como la Unión de Uniones Ejidales y Grupos Campesinos Solidarios, en Chiapas; la Alianza de Organizaciones Campesinas Autónomas de Guerrero y la Coalición de Ejidos Cafetaleros de la Costa Grande, en Guerreo; la Coordinadora Estatal de Productores de Café de Oaxaca y la Unión de Comunidades Indígenas de la Región del Istmo, en Oaxaca, entre otras (Sánchez 1999). 
principios y valores como la cooperación, la solidaridad, la acumulación y distribución comunitaria de la riqueza, el respeto irrestricto por los recursos naturales, la democracia participativa, así como el comercio justo y orgánico (Santos 2002).

Destacan experiencias con enfoques autogestivos, participativos y sustentables, con propuestas alternativas de cogestión y cooperación no gubernamental. Por ejemplo, la experiencia de la Coalición de Ejidos del Yaqui y del Mayo en la década de 1980, así como diversas experiencias cooperativas, de pescadores yaquis y mayos en Sonora y Sinaloa, mayas en Quintana Roo, comunidades forestales de las selvas tropicales o bosques templados, así como las cooperativas independientes de pequeños productores indígenas de café orgánico bajo sombra en Chiapas, entre muchos otros (Toledo 1992). Ejemplos más radicales son las experiencias populares en la mixteca oaxaqueña, en Yosotato y Yosonotú, los 38 municipios autónomos creados por el Ejército Zapatista de Liberación Nacional en Chiapas, el municipio Rancho Nuevo de la Democracia en Guerrero, la Policía Comunitaria en Guerrero, las organizaciones autónomas municipales de los ayüük (mixes) de Quezaltepec y de los tinujéi (triquis) de San Juan Copala en Oaxaca, así como las autodefensas comunitarias en Michoacán, así como el llamado mercado alternativo de economía solidaria basado en la moneda local sustituta reconocida como túmin, que comenzó entre los tachihuiin de Veracruz y se ha extendido a otras partes del país.

\section{EJES DE REFLEXIÓN SOBRE EL PORVENIR}

La profundización de las políticas neoliberales supone una guerra contra los pueblos originarios, donde se confunden las fuerzas legales y coercitivas del Estado con las empresas capitalistas, incluyendo las del crimen organizado. Tiene como resultado la invasión de territorios, el despojo de sus lugares de residencia y modos productivos tradicionales, el saqueo de recursos, la afectación del medio ambiente, la criminalización de la movilización y las resistencias, la usurpación autoral y de patentes por corporativos privados sobre sus patrimonios bioculturales, todo lo cual amenaza a la supervivencia de estos pueblos y sus formas vitales.

El concepto de desvío de poder permite tipificar los crímenes que han cometido reiteradamente los últimos gobiernos de todos los partidos políticos. Se define como uso faccioso del derecho y los poderes del Estado para favorecer en forma unilateral los intereses de los grandes capitales transnacionales, así 
como para perseguir y afectar las garantías de los pueblos..$^{21}$ Para ello, se aplica una ingeniería constitucional e institucional dolosa que configura un estado de guerra social permanente y de ocupación interna, una situación estructural, sistemática y de largo plazo por cuyo conducto el edificio jurídico del Estado abre el margen de maniobra a las corporaciones, mientras cierra los canales legales a la población, obstaculizada los anhelos de justicia de las mismas entidades que deberían defenderla. Se manifiesta en despojos violentos, fragmentación y devastación como programa de gobierno y en abandono por parte del Estado de su deber primordial de velar por el interés público para satisfacer, en cambio, los de corporaciones y grupos particulares. El Estado, en su ejercicio institucional y jurisdiccional, al actuar como guardián de los intereses privados, utiliza su capacidad coercitiva contra toda discrepancia u oposición al modelo. El concepto se complementa con el de terrorismo de Estado, una política estatal planificada y ejecutada para combatir por medios ilegales las luchas sociales, con la finalidad de justificar la suspensión de las garantías constitucionales, el establecimiento de estados de excepción y la violación de derechos humanos (López y Rivas 2014).

La fase actual de acumulación de capital por desposesión puede ser entendida como una nueva guerra de conquista, donde el mercado convierte en mercancías bienes que antes eran ignorados o permanecían fuera del circuito mercantil; se basa en la intensificación de la transferencia y apropiación de los recursos naturales, apostando a los altos precios de las materias primas en los mercados globales. Gran parte de estos se extraen de territorios indígenas y están siendo privatizados gracias a la desregulación para el cambio en el uso del suelo y la extracción masiva de recursos. Las corporaciones actuales, con relaciones orgánicas en el gobierno, a veces con capital obtenido mediante narcotráfico u otras formas económicas ilegales, se han vuelto muy eficientes para obtener información estratégica y lograr dividir a las comunidades para alcanzar sus propósitos al menor costo. En los medios y en el cabildeo político logran además que la respuesta enérgica de las sociedades indígenas sea intencionalmente tergiversada como ejemplos de quienes se oponen al progreso (O’Conor 2001, Sánchez et al. 2001, Harvey 2004).

Estos pueblos generalmente son invisibles en la planificación del desarrollo económico global. Por ello, los megaproyectos han dado lugar al despojo masivo

${ }^{21}$ La «desviación de poder», ha sido conceptualizada como «la utilización de la ley para impedir el acceso a la justicia», «el Estado usando sus atribuciones y poderes para beneficiar intereses particulares que son contrarios y perjudiciales al interés general por el que debería velar» (TPP 2014). 
de tierras y recursos naturales en territorios indígenas y campesinos, pero nunca a modelos que los incluyan como socios de los negocios manteniendo la propiedad y posesión de sus territorios. Los negocios asociados suelen abarcar áreas tan diversas como biotecnología, minería, energéticos, explotación forestal, ordenamiento territorial, infraestructura, pesquerías, producción agroalimentaria, comercio, sistemas formales e informales de crédito, seguros, servicios, telecomunicaciones y turismo. En buena medida, la forma de realizar estas transacciones provoca efectos muy deletéreos en el entorno donde se instalan, desde una precarización desproporcionada y la falta subsecuente de ingresos y empleo, pérdida de tierras y devastación de recursos naturales, pobreza persistente en el largo plazo, éxodo y desplazamiento forzado de individuos y familias, ingobernabilidad, violencia y conflicto social, corrupción de autoridades y representantes comunitarios, profundización de las prácticas discriminatorias, violación sistemática de derechos humanos y consolidación de poderes de facto informales e ilegales. A nivel local, estos procesos suelen traducirse en inquietud y movilización, que tienden a articular a comunidades y grupos de población indígena migrante, organizaciones civiles y sociales, algunos sectores de las asociaciones religiosas y organismos académicos, que se polarizan en debates y reivindicaciones con funcionarios de gobierno, bancos, cámaras de comercio y empresariales, locales y transnacionales.

Hay que tener en cuenta que estamos en un entorno donde los actores y prácticas globales emergentes configuran sus posiciones respecto de tres cuestiones políticas de fondo, que incluyen la salvaguarda de los derechos humanos universales, la aplicación delimitada de los tratados de libre comercio y las nuevas formas de la cooperación internacional y nacional al desarrollo local contra la segregación y la desigualdad; en esta perspectiva, las organizaciones y comunidades de los pueblos indígenas deben aprender a interaccionar con organismos multilaterales o intergubernamentales, consorcios empresariales, agencias civiles de cooperación, entidades financieras, mafias del crimen organizado, mecanismos y protocolos comerciales, redes y flujos migratorios, medios de información y comunicación, así como la sociedad civil organizada.

En la actual coyuntura es imperativo articular las luchas indígenas y no indígenas de resistencia y defensa territorial , como avanzar en la recreación del Estado de derecho, con carácter social, democrático, equitativo y de respeto por los derechos humanos e indígenas. Vincular movimientos y enfoques que replantean el objetivo del desarrollo fomentado hasta ahora por el sistema económico y 
político neoliberal-global. José del Val (2012) ha propuesto, como elementos de política social para los pueblos indígenas en México: construir un nuevo pacto social, cuyo objetivo sea el replanteamiento total de la estructura constitucional en beneficio de las mayorías, con pleno respeto a la diversidad; establecer el reconocimiento y la codificación legal de los derechos y obligaciones de reparación del daño histórico y restitución de los recursos territoriales interculturales, lo que conlleva la remunicipalización del país y el reconocimiento de la autonomía y la autodeterminación; en un nuevo federalismo que asuma la interculturalidad en todos los sistemas y niveles educativos, así como regular lo necesario para detener el deterioro de los recursos naturales.

Los ejidos y comunidades de los pueblos indígenas y campesinos deben conocer sus derechos y la forma en que actualmente están amenazados por los cambios legislativos. Saber que cualquier autorización para el uso, goce o afectación de sus territorios debe aprobarse en asambleas duras, con mayoría calificada. En caso de la imposición de servidumbres legales u ocupación temporal, los pueblos tienen la opción de resistir legítimamente al desplazamiento y denunciar la violación de sus derechos, así como la inconstitucionalidad de la imposición de proyectos que afectan otros derechos constitucionalmente reconocidos, como el derecho al agua, la alimentación, la vivienda, el trabajo, el medio ambiente sano o la cultura.

Es impostergable que revisemos procesos y nociones que se nos imponen en nombre del desarrollo, que ya no se basan en el interés público y el bien común sino en la rentabilidad de los flujos de inversión del capital financiero transnacional, donde los Estados usan esa retórica para ocultar y justificar su sujeción a la imposición de tratados de libre comercio y desregulaciones arancelarias, pero no para garantizar la salvaguarda de los derechos humanos en general y de los pueblos en particular. En este sentido, la relevancia de la discusión y movilización por la defensa, el reconocimiento jurídico y la protección legal de sus territorios, radica en que de ello depende la sustentabilidad en la diversidad biocultural del país. Esos patrimonios territoriales están ya subastados por el Estado mexicano para la extracción público-privada de minerales e hidrocarburos, el saqueo de genomas y conocimientos locales, a la par de la inserción de especies transgénicas y la usurpación de particulares sobre el control de los recursos hídricos; todo este despojo conlleva el desplazamiento forzado de grandes grupos de población ya pauperizada y la cancelación de las condiciones materiales y espirituales de reproducción social de muchas comunidades originarias. 
Estamos ante un cambio de época respecto de las alianzas estratégicas necesarias para la lucha por el interés de la nación. Durante las últimas dos décadas hemos vivido acontecimientos sociohistóricos de coyuntura que han derivado en renovados o emergentes factores de riesgo y amenaza para la integridad y los intereses colectivos de los pueblos en sus territorios: a) los efectos del cambio climático agravados por los cambios en los modos de producción agropecuarios y agroforestales tradicionales, como en los usos del suelo, lo que implica riesgos socioambientales en un amplio gradiente; b) la transformación legislativa y de política pública dirigida a la privatización de tierras y recursos naturales, con la consecuente desprotección normativa de los intereses colectivos de los pueblos, así como su entrega a los capitales y las empresas transnacionales y sus megaproyectos; c) la violencia armada generalizada en el país, que involucra poderes fácticos contra los que el Estado justifica la militarización de territorios y criminalización o cooptación de grupos comunitarios de autodefensa.

La nueva expansión del sistema financiero conlleva la transformación radical de espacios y redes sociales como formas políticas, en múltiples escalas geográficas y de manera simultánea, con una capacidad incrementada para la desestructuración de comunidades y sus formas de organización territorial, donde los pueblos no siempre están en posibilidad de reconstruirse en el largo plazo. El horizonte que emerge en esta segunda década del siglo es de amenaza y no podemos sino responder ante esta situación desde una posición de compromiso, que surge de reconocer una deuda ética con ellos y con nosotros mismos, pues cada vez que se pierde una conciencia étnica o un territorio ancestral se pierde también una parte de nuestro corazón colectivo. Debemos transformar las condiciones de riesgo que nos impone el modelo de desarrollo global, con un impacto diferencial que se manifiesta actualmente en forma desproporcionada en contra de los pueblos originarios, por el despojo masivo de sus tierras y recursos naturales, así como por el desplazamiento incrementado de sus comunidades. No podemos soslayar la responsabilidad de las instancias gubernamentales y la omisión en el desempeño de sus atribuciones, como tampoco minimizar nuestro papel como actores interesados en el porvenir de la nación y su soberanía, destino que compartimos con los pueblos indígenas. 22

22 Llama la atención que CONAGUA sea uno de los organismos más denunciados por parte de las comunidades en el país por brindar servicios a intereses privados, sin ejecutar las sentencias de los tribunales ni respetar las decisiones de comunidades y movimientos. Igualmente son importantes las denuncias contra la Comisión Nacional para el Desarrollo de los Pueblos Indígenas (CDI), la Comisión Nacional de Derechos Humanos (CNDH), la Secretaría de Medio Ambiente y Recursos 


\section{FUENTES DE CONSULTA}

Ánimas, Leticia, 2014, «18 pueblos indígenas afectados por concesiones petroleras», Regeneración, 18 de noviembre, <http://regeneracion.mx/defensa-petroleo/18-pueblos-indigenas-afectados-por-concesiones-petroleras/> [consulta: 01 de diciembre de 2014].

Barabas, Alicia, 2004, «La territorialidad simbólica y los derechos territoriales indígenas: reflexiones para el estado pluriétnico», Alteridades, 14(27), pp. 105-119.

Bartolomé, Miguel y Alicia Barabas, 1990, La presa Cerro de Oro y el ingeniero el Gran Dios. Relocalizacion y etnocidio chinanteco en Oaxaca, 2 vols., Instituto Nacional Indigenista / CONACULTA / INAH, México.

Bastida Muñoz, Crescencio Mindahi y Geraldine Patrick, 2006, El Convenio sobre Diversidad Biológica y el artículo 8 (j). Pueblos originarios de México, biodiversidad y derechos de propiedad intelectual colectiva, Coordinación General de Educación Intercultural y Bilingüe / Universidad Intercultural del Estado de México, México.

Becerril, Andrés, 2014, «SEGOB alerta que contratos mineros ponen en riesgo a pueblos indígenas», Excelsior, 19 de enero de 2014, <http://www.excelsior.com.mx/nacional/2014/01/19/939125> [consulta: 01 de diciembre de 2014].

Boege, Eckart, 2008, El patrimonio biocultural de los pueblos indígenas de México. Hacia la conservación in situ de la biodiversidad y agrodiversidad en los territorios indígenas, INAH / CDI, México.

, 2013, «El despojo de los indígenas de sus territorios en el siglo XXI», La Jornada del campo, 69, 15 de junio de 2013, <http://www.jornada.unam.mx/2013/06/15/ cam-mineria.html> [consulta: 01 de diciembre de 2014].

Campanur Salvador, 2014, "La defensa de los bosques del municipio autónomo de Cherán, Michoacán», en Fabiola Escárzaga, Raquel Gutiérrez, Juan José Carrillo, Eva Capece, Börries Nehe (eds.), Movimiento indígena en América Latina: Resistencia y transformación social, vol III, Universidad Autónoma Metropolitana, Xochimilco / Benemérita Universidad Autónoma de Puebla/ Centro de Investigaciones y Estudios Superiores en Antropología Social, México, pp. 59-64.

Castillo, Agustín del, 2013, «Los nayeri y la CFE en disputa por megapresa», Milenio, 29 de octubre de 2013, <http://www.milenio.com/region/nayeri-CFE-disputa-megapresa_0_180581950.html> [consulta: 01 de diciembre de 2014].

Centro Nacional de Comunicación Social AC (CENCOS), 2014, «México en grave riesgo ambiental: $10^{\mathrm{a}}$ Asamblea Nacional de Afectados Ambientales Declaratoria», en CENCOS web, 14 de octubre de 2014, <http://www.cencos.org/comunicacion/mexico-en-grave-riesgo-ambiental> [consulta: 01 de diciembre de 2014].

Chacón, David, Carlos Durand y Jorge Fernández (coords.), 1995, Efectos de las reformas al agro y los derechos de los pueblos indios en México, UAM-Azcapotzalco, México.

Naturales (SEMARNAT), la Comisión Nacional de Electricidad (CFE), así como el Congreso y el Senado nacionales, los congresos estatales y las autoridades municipales. Suelen coludirse para consumar los despojos. 
Comisión Interamericana de Derechos Humanos (CIDH), 2010, «Derechos de los Pueblos Indígenas y Tribales sobre sus tierras ancestrales y recursos naturales. Normas y jurisprudencia del Sistema Interamericano de Derechos Humanos», OEA, CIDH, <http:// www.oas.org/es/cidh/indigenas/docs/pdf/Tierras-Ancestrales.ESP.pdf> [consulta: 01 de diciembre de 2014].

Comisión Nacional para el Conocimiento y Uso de la Biodiversidad (CONABIO), 2006, Capital natural y bienestar social, México, CONABIO, <http://www.conabio.gob. mx/2ep/images/c/c5/capital_natural_1.pdf> [consulta: 01 de diciembre de 2014].

Coordinación General de Minería (CGM), 2007, Anuario estadístico de la minería mexicana 2007, Secretaría de Economía, CGM, México.

Cornelius, Wayne A. and David Myhre (eds.), 1998, The Transformation of Rural Mexico: Reforming the Ejido Sector, Center for U.S.-Mexican Studies, University of California, San Diego, La Jolla.

Dávalos, Pablo, 2008, «El sumak kawsay («buen vivir») y las cesuras del desarrollo», en ALAl, América Latina en Movimiento, 6 de mayo de 2008, <http://alainet.org/active/23920> [consulta: 01 de diciembre de 2014].

De Grammont, Hubert y Héctor Tejera (coords.), 1996, Nuevos procesos rurales en México: Teorías, estudios de caso y perspectivas, 4 vols., UNAM / UAM / INAH, México.

Del Val, José, 2012, «Una nueva política social para los pueblos indígenas», México Social, 24, pp. 17-19, CEIDAS, México.

, 2014, «En un modelo extremo de desigualdad social», en México Social, 1 de enero, <http://mexicosocial.org/index.php/secciones/especial/item/439-en-un-modelo-extremo-de-desigualdad-social> [consulta: 01 de diciembre de 2014].

Espinoza Sauceda, Guadalupe. 2012. «De desalojos, desplazamientos y derechos de comunidades indígenas y campesinas por grandes represas. El caso de El Zapotillo en los Altos de Jalisco», en Luis Daniel Vázquez (ed.), Patrimonio biocultural, saberes y derechos de los pueblos originarios, Guadalajara, CLACSO, pp. 141-154. <http://biblioteca.clacso.edu.ar/clacso/coediciones/20121127111932/PatrimonioBiocultural pdf > [consulta: 01 de diciembre de 2014].

Gómez, Magdalena, 2015, «Los pueblos indígenas ante la inminente Ley de Aguas», La Jornada, 10 de marzo de 2015, <http://www.jornada.unam.mx/2015/03/10/opinion/018a2pol> [consulta: 10 de marzo de 2015].

Haro, Jesús Armando y Ramón Martínez Coria, 2015, «Salud para los pueblos indígenas de México, avances y retrocesos a la vuelta del milenio», en Esther Jean Langdon y Marina D. Cardoso (orgs.), Políticas comparadas em saúde indígena na América Latina, Florianópolis, Universidad Federal de Santa Catarina (en prensa).

Haro, Jesús Armando, 2013, «Prevención del desplazamiento forzado. Los guarijíos de Sonora y el proyecto de presa Bicentenario (Los Pilares)», en Oscar Torrens (ed.), El desplazamiento interno forzado en México. Un acercamiento para su reflexión y análisis, CIESAS / El Colegio de Sonora / Senado de la República / Miguel Ángel Porrúa, México, pp. 185-212.

Harvey, David, 2004, El nuevo imperialismo, Akal, Madrid.

Instituto Nacional de Estadística y Geografía (INEGI), 2010, "Censo de Población y Vivienda 2010. Conjunto de datos, viviendas», INEGl, <http://www.inegi.org.mx/sistemas/ 
olap/Proyectos/bd/censos/cpv2010/Viviendas. asp?s=est\&c=27875\&proy=cpv10_ viviendas> [consulta: 01 de diciembre de 2014].

Lamas Lorena y Gabriela Martínez, 2013, «Indígenas kumiai, los marginados de la Ruta del Vino», Milenio, 18 de noviembre, <http://www.milenio.com/bajacalifornia/Indigenaskumiai-marginados-Ruta-Vino_0_192580813.html> [consulta: 01 de diciembre de 2014].

López Bárcenas, Francisco y Mayra Monserrat Eslava, 2013, El mineral o la vida. Legislación y políticas mineras en México, Itaca, México.

López Bárcenas, Francisco, 2009, Legislación y derechos indígenas en México, Cámara de Diputados / Centro de Estudios para el Desarrollo Rural Sustentable y la Soberanía Alimentaria, México.

2013, «¿Qué hacemos con los indios? Pueblos indígenas y desarrollo: entre las políticas gubernamentales y el «buen vivir»», Papeles de Población, 19(77), pp. 177-192.

López Bárcenas, Francisco, Ana Hilda Ramírez y Ramón Martínez Coria, 1996, «Los mayos de Huites, desplazados por la presa», Estudios Sociales, 6(12), pp. 245-261.

López Bárcenas, Francisco, s. f., «Los movimientos indígenas en México: rostros y caminos», Página Web de Franciso López Bárcenas <http://www.lopezbarcenas.org/ sites/www.lopezbarcenas.org/files/Los\%20movimientos\%20indigenas\%20en\%20 Mexico\%20Rostros\%20y\%20caminos.pdf> [consulta: 01 de diciembre de 2014].

López y Rivas, Gilberto, 2014, «Los pueblos de México juzgan al Estado», Rebelión, 1 de febrero, <http://www.rebelion.org/noticia.php?id=180229> [consulta: 01 de diciembre de 2014].

Martínez Coria, Ramón, 1999, «El pueblo mayo de Huites, desplazado por la presa Colosio», Experiencias y perspectivas indígenas, México, INI, serie de Divulgación, 4.

Mittermeier, Russell y Cristina Goettsch, 1992, «La importancia de la diversidad biológica de México», en José Sarukhán y Rodolfo Dirzo (comps.), México ante los retos de la biodiversidad, CONABIO, México, pp. 57-62.

Moreno, José Luis. 2014. Despojo de agua en la cuenca del río Yaqui, El Colegio de Sonora, Hermosillo.

Nahmad, Salomon, 2001, «Impact of hydroelectric dams on indigenous people, chinantecos, otomíes and huicholes: a case study from México», Dams knowledge base serial no: soc165, <http://www.dams.org/kbase/submissions/showsub.php?rec=soc165> [consulta: 01 de diciembre de 2014].

Nava Negrete, Alfonso y Enrique Quiroz Acosta, 2007, «Concesión administrativa», México, en Instituto de Investigaciones Jurídicas, Diccionario Jurídico Mexicano, tomo A-C, UNAM-Porrúa, México.

Navarro Ramírez, Adriana, 2014, "Retos de la minería en México», Este País, 1 de diciembre de 2014, <http://estepais.com/site/2014/retos-y-perspectivas-de-la-mineria-en-mexico/> [consulta: 01 de diciembre de 2014].

O'Conor, James, 2001, Causas naturales. Ensayos sobre marxismo ecológico, Siglo XXI Editores, México.

Organización de las Naciones Unidas (ONU), 2013, Estudio sobre las industrias extractivas en México y la situación de los pueblos indígenas en los territorios en que 
están ubicadas estas industrias (E/C.19/2013/11), Consejo Económico y Social, Foro Permanente para las Cuestiones Indígenas, Nueva York, <http://www.un.org/esa/ socdev/unpfii/documents/2013/E_C19_2013_11s.pdf> [consulta: 01 de diciembre de 2014].

Organización Internacional del Trabajo (OIT) 1989, Convenio sobre pueblos indígenas y tribales, OIT (núm. 169), <http://www.ilo.org/dyn/normlex/es/f?p=NORMLEXPUB:12100:0::NO::P12100_INSTRUMENT_ID:312314> [consulta: 01 de diciembre de 2014].

Ramos, M., 2004, «Negociación internacional y desarrollo sostenible», Mesa redonda Desarrollo Sostenible "Alternativa XXI: La distribución social del conocimiento», Feria Internacional del Libro Universitario, Xalapa, 10 de septiembre.

Robinson, Scott S., 2012, «Megaproyectos: presas, minas y demás...» La Jornada del Campo, 57, 23 de junio, <http://www.jornada.unam.mx/2012/06/23/cam-minas. html> [consulta: 01 de diciembre de 2014].

Robles Berlanga, Héctor, 2012, «Saldos de las reformas de 1992 al Artículo 27 constitucional», Estudios Agrarios. Revista de la Procuraduría Agraria, 38, pp. 147-155, <http://www.pa.gob.mx/publica/rev_38/H\%C3\%A9ctor\%20Msnuel\%20Robles\%20 Berlanga.pdf> [consulta: 01 de diciembre de 2014].

Salas, Marcela, Sergio Bibriesca, Joana Moncau, Gloria Muñoz y Spensy Pimentel, 2011, «Un recorrido por el despojo y la resistencia en el territorio indígena de México», Des/nformémonos, 1 de marzo, <http://desinformemonos.org/PDF/REPORTAJE_ ESPECIAL2.pdf> [consulta: 01 de diciembre de 2014].

Sánchez Rubio, David, Norman J. Solórzano Alfaro, Isabel V. Lucena Cid (eds.), 2001, Nuevos colonialismos del capital. Propiedad intelectual, biodiversidad y derechos de los pueblos, Icaria, Barcelona.

Sánchez, Consuelo, 1999, Los pueblos indígenas: del indigenismo a la autonomía, Siglo XXI Editores, México.

Santos, Boaventura de Sousa (coord.), 2002, Produzir para vivir: os caminos da produção capitalista, Editora Civilização Brasileira, Brasilia.

Sariego Rodríguez, Juan Luís, 2010, «De minas, mineros, territorios y protestas sociales en México: los nuevos retos de la globalización», Cahiers des Amériques Latines, n. 60-61, pp. 173-192.

Suprema Corte de Justicia de la Nación (SCJN), 2013, Protocolo de actuación para quienes imparten justicia en casos que involucren derechos de personas, comunidades y pueblos indígenas, SCJN, México, <http://www.sitios.scjn.gob.mx/codhap/ Protocololndigena/inicio.html> [consulta: 01 de diciembre de 2014].

Toledo, Víctor M., David Garrido y Narciso Barrera-Bassols, 2013, "Conflictos socio-ambientales, resistencias ciudadanas y violencia neo-liberal en México», Ecología Política. Cuadernos de Debate Internacional, 46, pp. 115-124.

Toledo, Víctor Manuel y Narciso Barrera-Bassols, 2008, La memoria biocultural. La importancia ecológica de las sabidurías tradicionales, Icaria, Barcelona.

Toledo, Víctor Manuel, 1992, «Utopía y naturaleza. El nuevo movimiento ecológico de los campesinos e indígenas de América Latina», Nueva Sociedad, 122, pp. 72-85. 
Tribunal Permanente de los Pueblos (TPP), 2015, «Sentencia de la audiencia final del Capítulo México 2014», en web TPP, <http://www.tppmexico.org/sentencia-de-la-audiencia-final-del-capitulo-mexico-del-tpp/> [consulta: 01 de diciembre de 2014].

Fecha de recepción: 9 de junio de 2014 Fecha de aceptación: 8 de abril de 2015 